\title{
The Obstacles Faced by the Learners in the Learning of Quadratic Inequalities
}

\author{
Judah Makonye (Dr) \\ School of Education, University of Witwatersrand, Number 27 St Andrews Road, \\ Parktown, 2193, Johannesburg, South Africa \\ Email: Judah.makonye@wits.ac.za
}

Mhonda Shingirayi (Mr)

Lamula Jubilee High School, Meadowlands, Soweto, Johannesburg, South Africa

Email:skmhonda@gmail.com

\section{Doi:10.5901/mjss.2014.v5n27p716}

\section{Abstract}

Quadratic inequalities is one section of algebra were learners tend to lose out marks in high stakes school leaving examinations. A total of 27 grade 11 learners from a public school in Soweto, Johannesburg participated in this study. The learners responded to a written task consisting of quadratic inequalities tasks in order to establish the kinds of errors they held and the misconceptions thereof. The written tasks, together with the interview responses were analysed to find out the types of errors as well as the possible reasons behind those errors. Procedural and conceptual errors linked to algebraic processes, as well as meaning systems confusing equations and inequalities were prevalent. One of the recommendations is for learners to start solution of quadratic inequalities through trial and error by substituting integer values in quadratic inequalities so that an intuitive understanding of solution to quadratic inequalities is established.

Keywords: quadratic inequalities, alternative conceptions, learning

\section{Introduction}

This study is about the obstacles that Grade 11 learners face when they solve quadratic inequalities. It was undertaken by a pair of researchers; one based at a School of Education at the University of Witwatersrand, Johannesburg, South Africa and the other who is a mathematics teacher at Lamula Jubilee High School; a township school in the same city.

Mathematics is generally regarded as one of the most problematic learning areas in the curriculum. If learners' end of term results are considered mathematics is one of the learning areas which consistently has the lowest marks on the report cards. In this vein, Milgram (2005) indicated that mathematics is one of the most seriously misunderstood subjects in the education system. If these sentiments are correct one would really wonder why learners perform dismally in this learning area.

Worldwide, a lot of research has been conducted in mathematics and various factors have been put forward as the reasons that make learners fail the subject (for example see Dibakar, 2012; Dursun \& Dede, 2004; Makgato \& Mji, 2006). The nature of mathematics, teaching methods, assessment styles and the cognitive difficulties learners face were among the reasons cited as contributing towards poor performance in mathematics outcomes.

In our experience, the claims are a true reflection of what transpires in most high schools. Most learners do not feel comfortable with mathematics. This can be evidenced by the fact that in South African schools, at grade 10 levels, most of the learners choose to study Mathematical Literacy rather than Pure Mathematics. In general, most people find mathematics dull and difficult and dislike it (Dibakar, 2012). Dibakar further suggests that many people feel an extreme dislike, even fear of mathematics that Lazarus (1974) called mathophobia.

Mathematics is unlike other fields of human endeavour, in that it is usually viewed as a subject of great precision in which concepts can be defined accurately to provide a sound background for mathematical theory (Tall \& Vinner 1981). This view of mathematics indicates that great precision is a requirement for anyone to do well in the subject. This probably explains the reason why most learners struggle with the subject because they fail to carry out the prescribed steps in getting to a solution with the great precision required in the subject.

The manner in which students grasp mathematical concepts is largely dependent on their understanding. Skemp (1976) classified understanding into two categories namely relational understanding and instrumental understanding. 
According to Skemp (1976) relational understanding means 'knowing both what to do and why'. This appears to be an area of concern in mathematics education. Not many learners are in a position to apply correct methods and comprehend the reason why they had to do what they did in problem solving. Instrumental understanding is regarded as "rules without reasons" Skemp (1976). In this case there is no clear linkage of mathematical concepts; mathematical knowledge is seen as unrelated but just tool kit to find answers to numerical questions (Luneta and Makonye, 2012).

In most township schools, the number of learners doing Mathematical Literacy, is twice or thrice the number of learners doing Pure Mathematics. There are always efforts to increase the number of pupils studying mathematics and science. This is because the number of learners doing maths and science is less than what the nation expects for its manpower needs.

The fear and resentment that many learners have of mathematics has stimulated studies to find out why to a large extent the learning of mathematics is so difficult and ineffective. In their study of learner errors and misconceptions Luneta and Makonye (2012) observed that the poor performance in Mathematics is correlated to learner errors and misconceptions.

\subsection{Problem Statement}

Riccomini (2005) observed that a majority of the teachers do not take notice of the misconceptions that their learners make. If this claim is true, then it would mean that for teachers it is "business as usual" when they are in the classrooms. However the possible reason why teachers are unaware of their learners' errors could be better be described by Nesher's (1997) remarks who indicated that learner errors and misconceptions are difficult to identify. The reason being that at times learners may obtain "right" answers for wrong reasons.

Most learners lose marks on solving of quadratic inequalities at Grade 12 school leaving examinations. We feel that the marks that they lose in this section of General Algebra are marks that they could easily obtain. We would like to find out why most of the grade 12 learners struggle with the solving quadratic inequalities on tasks such as: Solve for $x$ in, $x^{2}-x \geq 6$. Among the problems faced by the learners is that they change the quadratic inequality to an equation instead. In doing so the inequality sign "vanish" and are then replaced by equal signs. In the end learners come up with roots to an equation instead of the solution to an inequality.

Factorisation of the quadratic inequality appears to be one of the challenges that learners have, and as a result they end up obtaining wrong critical values of the problem at hand. Reading the solution from the diagram or the number line tends to be a common problem among most of the learners. It is against this multitude of problems faced by the grade 12 learners that the researchers would want to find out what are the causal factors.

We argue that learners do not come into the mathematics classroom with "clean" minds. Learners bring with them ideas and values about mathematics formulated on their own or have obtained from previous educational experience (at home or in school). Some of the knowledge that these learners have does not make sense. Some prior knowledge that the learners have before the lesson may be incorrect and this leads them to getting wrong solutions when the learners attempt to solve problems. Smith, DiSessa \& Roschelle (1993) acknowledge that the errors and misconceptions made by the learners in learning mathematics and physics are generally common throughout the world. This shows that errors and misconceptions are an integral part in the learning of science subjects.

\subsection{Aim of the study}

The purpose of the study is to explore the learners' errors and misconceptions on solving quadratic inequalities.

\subsection{Research Questions}

(i) What are the types of errors that the grade 11 learners have on solving quadratic inequalities?

(ii) What are the possible sources of students' incorrect solutions?

\subsection{Significance of the study}

This paper is written in the spirit of philosophers, Charles Pierce and Karl Popper's arguments. Pierce (1958/1887) argued that it is the incidence of doubts in our belief systems that propels us to question them in order to correct them. In the same way Popper (1963) argued that the growth of scientific knowledge strongly hinges on our ability to detect errors in our practice. This philosophy subsumes this study on learner errors in mathematics. 
This study explores learners' errors and misconceptions on quadratic inequalities. The study would be in a position to unearth the underlying problems faced by grade 11 learners in solving quadratic inequalities. It would be of help to us and fellow colleagues in the mathematics teaching fraternity, in the sense that the problems would have been identified as well as possible ways of to deal with them will be recommended by the study.

Cox (1975) suggested that it is quite beneficial to analyse errors as a way of obtaining information for use in planning individualised instruction. These sentiments indicate that if we as researchers become aware of the problems faced by the learners in solving quadratic inequalities, we would be better equipped with the knowledge on advising teachers on how to deliver the content in a much more effective and efficient way. Nesher (1987) also observed that teachers should be cognisant of their students' likely mistakes and include them into their lesson planning. As a result of this, the learners would be the ultimate beneficiaries of the study, since there is likelihood that current errors and misconceptions being faced by the learners would be exposed so that they can be adequately addressed by teachers.

\section{Conceptual Framework and Literature Review}

\subsection{Conceptual framework}

In this research study on the obstacles faced by the learners on the topic quadratic inequalities our discourse will be enlightened by constructivist theory of learning. This theory assumes that concepts are not taken unchanged directly from experience, but that a person's ability to learn and what they learn depends on the quality of the ideas that they bring to new experience. Knowledge is not entirely derived from experience but is regarded as a combination of experience as well as one's current knowledge structures.

It is common knowledge that a person's mind is active most of the time and on each occasion that the mind receives information, the next step is that of processing that information so that it makes sense or is usable. Oliver (1989) asserts that it cannot be assumed that knowledge can be transferred intact from one person to another, where the learner is viewed as a simple recipient to take it as is. This view is also shared by Luneta and Makonye (2012) who suggested that learners come into the classroom with relatively homogeneous, important views of mathematics, capable of assimilating and valuing mathematical understanding when the subject is being taught. The assertion that learners do not come into the classroom as "empty vessels" that need to be filled with knowledge is quite realistic during the introduction of a new topic. If a teacher throws some probing questions to the learners as a way of assessing what they already know, they will find out that learners will respond to most of the questions, although the responses might not be necessarily correct. The fact that learners provide some responses to the questions given to them confirms that they have some idea of their own when they come into the classroom.

The constructivist theory of learning regards the learner as an active participant in the construction of his/her own knowledge, and the learner's existing ideas and new ones interact, the new ideas being interpreted and understood in the light of the learner's present knowledge with its foundations on the previous experience (Hatano, 1996; Cobb, 1994). The learning activity according to the constructivist perspective is not a matter of adding, or of stockpiling new concepts to the ones that the learners already have but rather leads to changes in our schema.

Siegler (1995) argued that there are two very important aspects that need to be understood namely assimilation and accommodation which are defined as follows: assimilation is incorporation of some new recognisably familiar encountered idea into an existing schema (interrelated ideas in the mind) and accommodation is when the new idea is quite different from the existing schema and cannot be assimilated; then reconstruction and re-organisation take place so that a new schema is formed. Thus to the constructivist, learning leads to changes in our schemas according to Olivier (1989).

Olivier (1989) ' propounds that misconceptions are of paramount importance to teaching and learning, because misconceptions constitute a learners conceptual structure that will interact with new concepts and influence new learning.

\subsection{Definitions and key concepts}

Makonye (2011) refers to an error as a mistake, slip, and deviation from accuracy. This occurs if learners provide responses that are not in line with expected answers. Riccomini (2005) propounds that unsystematic errors are not intentional wrong answers and do not frequently occur and can be readily rectified by the learners themselves. Systematic errors though, are regarded as wrong responses that keep on happening. These are made methodically and displayed frequently in the learners work. Systematic errors are a manifestation of a faulty line of thinking, referred to as a misconception (Nesher, 1987; Riccomini 2005). 
Example

Solve for $\mathrm{x}$ in $x^{2}-3 x+2 \geq 0(x-1)(X-2)=0 x=2$ or $x=1$

In this example a learner correctly knows how to factorise the algebraic expression but he turns the quadratic inequality into a quadratic equation. Cox (1975) suggested that a child making such type of error must make it in similar problems at least three out of five times before it is considered a systematic error. The number of times that an error occurs distinguishes systematic errors from random errors. In random errors there is no recurrence of errors to provide evidence of incorrect thinking process or recording even though the errors occur in three out of five problems.

Smith, Di Sessa and Roschelle (1993) indicated that errors are noticeable in the written work of the learners or in their speech. They further suggested that misconceptions cannot be easily identified since they can be hidden in correct answers by mere coincidence where as they may not understand the logic or the reasoning behind what they did to obtain the correct answer. In such cases, the learner's misconceptions will be covered in their correct responses to questions.

\subsection{Possible sources of students' errors}

Errors and misconceptions may also result from gaps in Algebra (Makonye, 2011). algebraic operations such as removing brackets and factorisation pose a challenge in the solving of quadratic inequalities. If learners fail to correctly factorise a given quadratic inequality they would end up having wrong critical values that would in turn result in a wrong solution.

The kinds of knowledge held by learner may also cause misconceptions in mathematics. The knowledge that learners have may be classified as either procedural or conceptual (Hiebert and Leferve, 1986). Conceptual knowledge is generalisable knowledge that is full of links. Procedural knowledge is regarded as competence of carrying out a mathematical task, the know-how of doing calculations and knowledge of mathematical notation but not the know-why. So procedural knowledge with little or no conceptual knowledge will result in erratic performance.

\section{Research Methodology}

This study was aimed at exploring the learner's errors and misconceptions on solving quadratic inequalities.

\subsection{The Research design}

The study was carried out through qualitative methods. Qualitative research is generally defined as any form of research that produces findings that are not achieved as a result of statistical procedures or other methods of quantification Golafshini (2003). Cohen, Manion and Morrison (2002) also argue that qualitative research produces findings based from real world settings whereby information comes out naturally from participants. Merriam (1992) indicated that the aim of qualitative research is to attain a thorough understanding of certain aspects by going deeper than the surface of a situation. This view is also shared by Cresswell (2008) who suggested that qualitative research attempts to portray information as experienced by the people who took part in the study. In other words the use of qualitative research enhances the collection of first-hand information from the participants of the study. Thus qualitative research enables reliable and valid interpretations of learners' meaning systems that pre-dispose them to make the errors they make. Qualitative methods also reveal the knowledge gaps in quadratic inequalities which are experienced by the participants; it also helps us to understand learners' errors from their point of view.

\subsection{Sampling}

For the purposes of this study, the researchers used non-probability purposive sampling. According to Patton (1990) purposive sampling enables the collection of more information from a small number of carefully chosen cases. Merriam (1992) suggested that the rationale of purposive sampling is to enable the researcher to acquire knowledge about the research problem and therefore has to choose a sample that has characteristics of the issues under research.

The research study was conducted at Lamula Jubilee Secondary School in Soweto, Johannesburg, South Africa where one of the researchers taught mathematics. Participants were drawn from a Grade 11 mathematics class consisting of 27 learners of whom were 12 boys and 15 were girls. The average age of the learners was 17,2 years. Before the data collection, the learners had been taught quadratic inequalities for a period of two weeks as stipulated in the national curriculum statement. 


\subsection{Data collection methods}

These consisted of written tasks and interviews.

\subsubsection{Written task}

The learners were given a written task of about 40 minutes consisting of eight questions on solution of quadratic inequalities. The tasks were selected from previous examination questions as well as from a grade 11 mathematics text book. The questions varied in nature as well as the degree of their complexity.

The examples of the questions that were administered in the task include questions such as; Solve for $x$ in $x^{2}-2 x>-1$; as well as solve for $x$ in $(x-1)(x-2) \leq 6$. The participants were instructed to show all the working to enable the researchers to analyse as well as to make through observations of the types of errors made by the learners.

Strict control measures were taken to ensure that no participants had access to reference material during the writing of the task. This was easily attained by asking the class to put away their bags. The learners were also requested to sit at least a metre apart from each other in order to minimize interactions among themselves. Selected learners were interviewed to explain errors and misconceptions observed in their answers.

\subsubsection{Interviews}

The interview questions were mostly generated from the learners various responses from the written tasks. The advantage of using interviews is that the interviewer works face to face with the respondent to get first-hand the gist of participants' responses (Holsti, 1969; Yin, 1994). The interview also offered interviewers opportunities to probe or ask follow up questions to clarify issues so that learners would manifest their thinking. Also interviews enabled the researchers to gather information rapidly.

\subsection{Rigour}

According to (Yin, 1994)., anyone who conducts a qualitative research should be concerned with the validity and reliability of the study. Reliability implies obtaining consistent outcomes even if the research is done by different researchers using the same methods and procedures. Validity concerns whether the data that is collected is the data that was intended in the first place (Golafshani, 2003). This study strove to maintain these.

Also, if research results are obtained without following proper ethical considerations, then those results are deemed invalid (Adams \& Schvaneveldt, 2011). The ethical rules stipulate that participation should be voluntary and the participants have to be fully informed about the study. The researcher also has to provide guarantees of anonymity and confidentiality of the participants. All these requirements were followed.

The learners that participated in the study came from one class. The 27 participants in this study was not representative of the Grade 11 mathematics classes in the school or the country. For that reason the researchers used convenience sampling. However in a qualitative research the representativeness of a sample is not an important factor as the results need not be generalised (Merriam; 1992).

\section{Data analysis}

This study investigated the types of errors that grade 11 learners had on quadratic inequalities as well as to find out the sources of the students' incorrect solutions.

\subsection{Question by question analysis of errors on Grade 11 task on Quadratic inequalities}

Question 1.1 Solve for $x$ in $x^{2}-3 x>0$

The performance on this question was not good. $87,7 \%$ of the learners did not obtain full marks, due to errors that they made when answering this question. The errors in this question involved wrong factorisation as well as the failure to read the solution from the graph or a number line. Below is an example a learner's work on the question. 


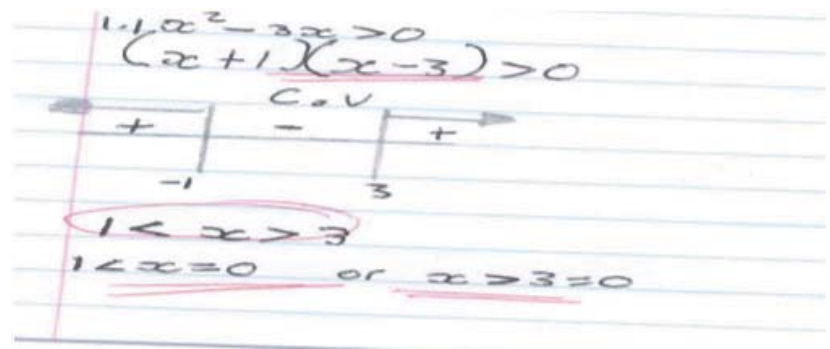

The learner did not factorise correctly, s/he may not have understood the idea of a common factor. This is an indication of a possible conceptual error. The learner goes on to draw the number line before solving for the critical values. There is a possibility that that the learners' procedural understanding is flawed and as a result of this made a procedural error.

Even if we condone the wrong critical values given by the learner and use the values that she obtained, the solution is wrong because of the way the inequality signs are written. The learner probably does not understand the meaning of inequality signs. This leads to another conceptual error.

Question 1.2 Solve for $x$ in $x^{2}-2 x>-1$

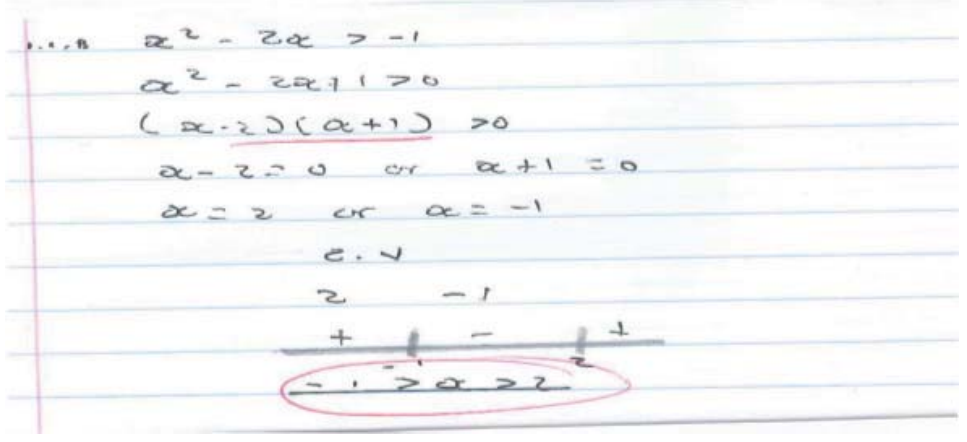

This learner transposed the constant term correctly. The first error was on factorisation instead of finding the factor of the constant term factorising, the learner wrote the factors of the middle term. This could be an indication that the learner lacks the conceptual knowledge of factorisation.

After factorising, the learner, changes the inequality problem to an equation, which is an indication that the learner might not know the difference between an inequality problem and an equation. This might be a careless mistake or a procedural error.

Question 2.1 Solve for $x$ in $2 x^{2}-2<3 x$;

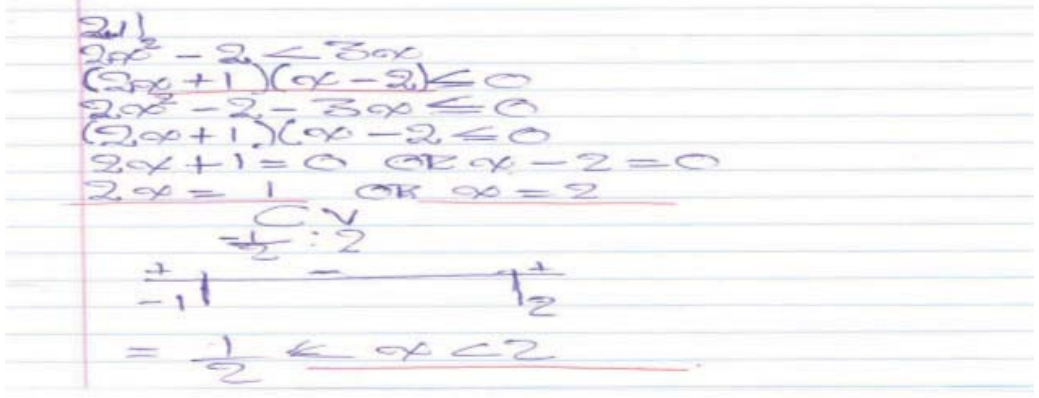

The learner factorises the expression before writing it in standard form. The factorisation is incorrect. The learner then transposed $3 x$ but changes the given inequality to less than or equal to sign. The problem is then changed to an equation. An equal sign is also included in the final answer.

Question 3.1 Solve for $x$ in $(x-1)(x-2) \leq 6$

The learners were expected to remove the brackets and write the expression in standard format i.e. $a x^{2}+b x+$ $c \leq 6$ 
$45 \%$ of the learners made errors when answering this question. The types of errors were either procedural or conceptual in nature. Below is an example of a written response from one of the learners.

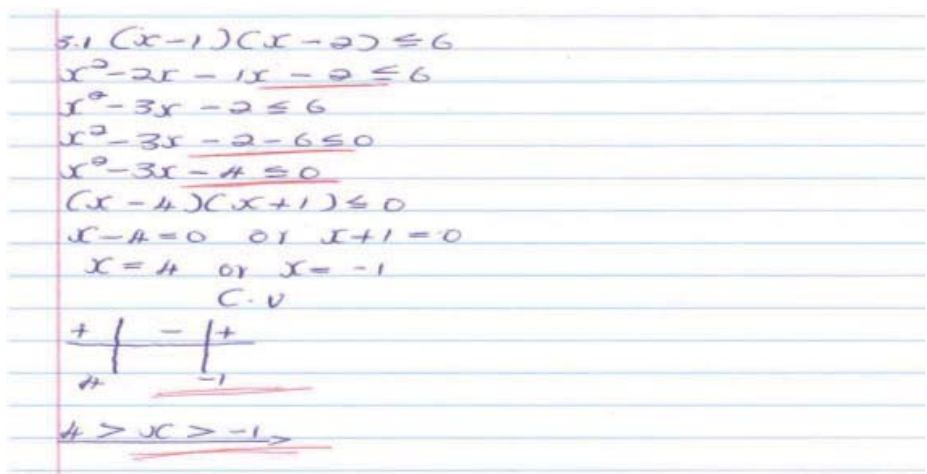

The learner did not remove the brackets correctly. The learners wrote the product of two negative numbers as a negative number. The second error was on the subtraction of terms. Both these errors are probably conceptual errors. The representation of the critical values on the number line was incorrectly done. The learner wrote the bigger number first instead of starting with the smaller critical value.

The table below quantifies correct and incorrect responses to the tasks given to participants. This shows to a great extend learners had many errors and misconceptions on this topic.

Table 1: Percentage of correct and incorrect responses to quadratic equation tasks.

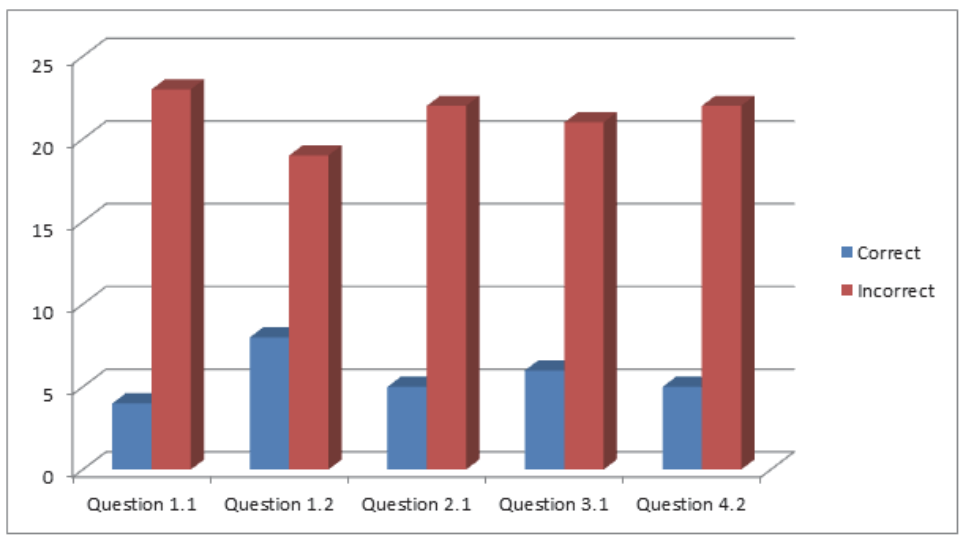

This table shows how widespread the learners' errors were in the solution of all the tasks.

\subsection{Analysis of Interview}

\subsubsection{Learner 1.}

The researchers asked the asked a learner the reason for his working.

Researcher 1: Why did factorisation precede the arrangement of the quadratic expression into the standard form? Learner 1: The re-arrangement of terms is not quite important since the factors are given by 2, the constant term.

Researcher 1: If you were solving a quadratic equation would you do that?

Learner 1: Yes I would still do that

Researcher 2: Why?

Learner 1: Because we still do that when we solve an equation...

This transcript shows that the learner was using the simple equation solving schema which he was not proficient at. His simple equation solving knowledge was not correct. Still he assimilated a new schema in an old defective schema. 


\subsubsection{Learner 2.}

Researcher 1: Why did you represent the critical values in the manner in which you did?

Learner 2: The four appeared on the left hand side followed by the negative one, so this is the way they should appear on the number line.

Researcher 1: But is it the correct solution?

Learner 2: Yes

Researcher 2: Why is it correct?

Learner 2: Because that is what I found.

This response clearly suggests that the learner does not check his answer against the original meaning of the problem. He thinks a solution is dependent on the algebraic processes and not on the original question. It did not appear to him that correct solutions would satisfy the original inequality if they the values were substituted.

\subsubsection{Learner 3}

On solution of a task, the learner reversed the inequality sign before multiplying or dividing by a negative one. This was followed by wrong factorisation and another change of the inequality sign. The critical values were then wrongly represented on the number line.

Researcher 2: Why do you keep on changing the inequality signs?

Learner: The negative sign does not really matter. However one just has to change the inequality sign until you arrive at the final answer.

Researcher 2: Please explain further?

Learner: Well sir, I am really scared by the inequality signs, I do not know how to handle them at all, they just make me very anxious!!!

\section{Discussion}

In general, learners used inappropriate schema to mediate their solutions to inequalities. They assimilated quadratic inequality solutions in the equation solving schema in cases where accommodation and not assimilation was needed. Learners held on to old ideas which also were not stable or correct to interpret the tasks. Incomplete schemas were used to interpret knew knowledge resulting in a snowball effect of spawning misconceptions from misconceptions and errors from errors. This resulted in highly incoherent erratic solutions.

Solving quadratic inequalities involves many steps which include writing the expression in standard form, factorising and or removing the brackets, finding the critical values, reading and interpretation the solution. It was clear that many learners had difficulties with the first step concerning factorisation of the given quadratic inequalities so as to establish the critical values.

Learners struggled to obtain the correct cognitive structure to solve quadratic inequalities. Learners were at a quandary as they were dealing with many interrelated concepts that they were supposed to sort out; correct factorisation, determining the critical values, determining and writing the values of $x$ in inequality form. Sometimes they were required to write the given inequalities in standard form first in which transposing and collecting like terms was necessary.

Some learners ignored the inequality signs and handled these as if they were equations. Some learners changed the signs; for example from greater than to less than without any specific logical reason. It was thus quite clear that learners were very anxious and could not handle the problems with inequality signs in a logical manner. Learners clearly lost control of their reasoning and all their work seemed to be guesswork. From the interviews it was clear that most learners did not have complete knowledge of handling the inequality signs. So we note that one of the problems learners have is that they experience mathophobia when they deal with inequalities. Lazarus (1974, p.16) introduced the term "mathophobia" which he defined as "...an irrational and impeditive dread of mathematics". We argue that most of the misconceptions in this study were caused by this dread.

\section{Conclusion}

This paper was written with the aim of exploring learner error types on quadratics inequalities tasks at Grade 11. It also explored the possible learner meaning systems to which those errors could be attributed. 


\section{Findings}

Chiefly, this study discovered that learners' errors on quadratic inequalities tasks lie in their lack of competency on basic algebraic processes. The research also found that in most cases learners made different kinds of errors in response to a single problem. This indicates that the process of error making is not static. More than $80 \%$ of the learners were not in a position to solve inequalities due to failure in algebraic processes, such as factorisation, transposing inequalities so that one side of the inequality became zero. In other cases, learners failed to determine the critical values of the quadratic equations inherent in the inequality. Where learners were able to transpose, they had challenges in assigning the correct signs. In some cases learners relegated the inequalities to equations, which equations they failed to solve because they had not yet mastered the factorisation procedure. The quadratic factorisation procedure is one that needs to be done with some understanding. Learners had many conceptual and procedural errors in factorisation. Learners showed clearly that their understanding of factorisation was in the main incomplete. Therefore far from exploring errors in solving quadratic inequalities per se, we found ourselves lodged in exploring errors in the "pathway processes" to solving inequalities such as factorisation and dealing with solution to quadratic equations. In as much as learners could not do these we had little hope to study the errors and misconceptions on the target task; solution of quadratic inequalities.

Interview questions showed that learners did not understand the difference between inequalities and equations. As a matter of fact they treated inequalities as if they were equations. The inequality tasks require complete relational and instrumental understandings and cannot be done without them. It was clear that learners did not have the deep surface procedures needed to solve such tasks. Learners were quick to use surface procedure for which they had little understanding as to why they were using them. Learners' had incorrect interpretation of the solution set from the quadratic factors. Learners were entangled in the schemas that they used but did not understand. Overwhelmed by the questions they simply did not know what they were doing and just used procedures for their sake. This led them to nowhere.

\section{Implications of the Study}

This study showed that most of the learners had errors due to algebraic processing and meaning of the inequality notion. In order to avoid many errors and misconceptions on the solution of quadratic inequalities, we recommended that;

- the differences between simple linear equations, quadratic equations and quadratic inequalities be discussed and understood by learners so that the schemata of each is differentiated

- solution of quadratic inequalities be first done through trial and error by substituting integer values in the inequalities so that solutions to inequalities become intuitively appreciated by learners

- factorization, solution of simple linear equations and quadratic equations be thoroughly understood before quadratic inequalities are studied

- that the meaning of solutions to quadratic inequalities be enhanced in the form of number lines or graphics so that conceptual understanding of solutions of quadratic inequalities is enhanced to avoid meaningless algebraic procedures which were endemic in this study.

\section{References}

Adams, G. R. \& Schvaneveldt, J. (2011). Understanding research methods. Longman Publishing Group: London.

Cobb, P. (1994). Learning Mathematics: Constructivist and Interactionist Theories of Mathematical development. Springer: New York.

Cohen, L., Manion, L. \& Morrison, K. (2002). Research Methods in Education. T. J. International Ltd: Padstow, Cornwall.

Cox, L. S. (1975). Systematic errors in the four vertical algorithms in normal and handicapped populations. Journal for Research in Mathematics Education, 6(4), 202-220.

Dibakar. S. (2012). Mathematics Performance at High School Certificate (HSC)

Dursun, S. \& Dede, Y. (2004). The Factors Affecting Students Success in Mathematics: Mathematics Teachers Perspectives. Journal of Gazi Educational Faculty 24(2), 217-230.

Examination: Predicting the Risky from Selected Student Variables.

Golafshani, N. (2003). Understanding Reliability and Validity in Qualitative Research. The Qualitative Report, 8, 597-607.

Hatano, G. (1996). A conception of knowledge acquisition and its implications for mathematics education. In P. Steffe, P. Nesher, P. Cobb, G. Goldin \& B. Greer (Eds.), Theories of mathematical learning (pp.197-217). New Jersey: Lawrence Erlbaum

Hatano, G. (1996). A conception of knowledge acquisition and its implications for mathematics education. In P. Steffe, P. Nesher, P. Cobb, G. Goldin, \& B. Greer (Eds.), Theories of mathematical learning (pp. 197-217). New Jersey: Lawrence Erlbaum.

Hiebert, J., \& Lefevre, P. (1986).Conceptual and procedural knowledge in mathematics. An introductory analysis. In J. Hiebert (Ed.), 
Conceptual and procedural Knowledge: the case of mathematics (pp. 1-27). Hillsdale, NJ: Lawrence Erlbaum.

Holsti, O. R. (1969). Content analysis for the social sciences and humanities. Reading, MA: Addison-Wesley

International Journal of Educational Sciences, 4(1): 35-42.

Lazarus, M. (1974). Mathophobia: Some Personal Speculations. National Elementary Principal, 53, 16-22.

MacGregor, M. \& Stacey, K. (1997). Cognitive models underlying students formulation of simple linear equations. Journal for Research in Mathematics Education, 24(3), 217-232

Makgato, M. \& Mji, A. (2006). Factors associated with high school learners' poor performance: a spotlight on mathematics and physical science, South African Journal of Education, 26(2)253-266.

Luneta, K. \& Makonye, J. P. (2012). Undergraduate students' preferences of knowledge to solve particle mechanics problems. Journal of science and mathematics education in Southeast Asia, 34 (2), 237 - 261.

Merriam, S. B. (1992). Case study research in education: A qualitative approach. San Francisco: Jossey-Bass

Milgram, J. R. (2005). The Mathematics Pre-Service Teachers Need to Know. Stanford University, Stanford: California.

Nesher, P.(1987). Towards an instructional theory: The role of students'misconceptions. For the learning of mathematics, 7(3), 33-39

Olivier,A. (1989). Presidential address delivered at the Thirteenth National Convention on Mathematics, Physical Science and Biology Education, Pretoria, 3 - 7 July. Pp.3-end.

Peirce, C. S. (1958/1887). The fixation of belief. In P. P. Weiner (Ed.) Selected writings. Pp. 91-113.

Popper, K. A. (1963). Conjectures and refutations: the growth of scientific knowledge. Harper \& Row, New York

Riccomini, P. J. (2005). Identification and remediation of systematic error patterns in subtraction. Learning Disability Quarterly, 28(3), 233-242.

Riccomini, P.J., (2005). Identification and remediation of systematic error patterns in subtraction: Volume 28. Clemson University.

Rolfe, G. (2006). Validity, trustworthiness and vigour: quality and the idea of qualitativ research. Methodological Issues in Nursing Education, 306-310.

Rolfe, G. (2006). Validity, trustworthiness and vigour: quality and the idea of qualitativ research. Methodological Issues in Nursing Education, 306-310.

Siegler, R.S. (1995). Cognitive variability. Developmental science, 10(1), 104-109.

Skemp, R. R. (1976). Relational understanding and instrumental understanding. Mathematics Teaching, 77, $20-26$

Smith, J. P., diSessa S. A. \& Roschelle, J. (1993). Misconceptions reconceived: A constructivist analysis of knowledge in transition. The journal of learning sciences $3(2), 115-163$.

Smith, J. P., Disessa S. A., \& Roschelle, J. (1993). Misconceptions reconceived: A constructivist analysis of knowledge in transition. The Journal of Learning Sciences, 3(2), 115-163.

Tall, D., \& Vinner, S. (1981). Concept image and concept definition in mathematics with particular reference to limits and continuity. Educational Studies in Mathematics, 12(2), 151-169.

Yin, R. K. (1994). Case study research: Design and methods. Thousand Oaks, CA: Sage Publications. 